Volume 8. No. 1.1, 2020

International Journal of Emerging Trends in Engineering Research

Available Online at http://www.warse.org/IJETER/static/pdf/file/ijeter2981.12020.pdf

https://doi.org/10.30534/ijeter/2020/2981.12020

\title{
Intelligent Tutoring Systems' Measurement and Prediction of Students' Performance Using Predictive Function
}

\author{
Siti Khatijah Nor Abdul Rahim ${ }^{1}$, Amir Hamzah Jaafar ${ }^{2}$, Suraya Masrom ${ }^{3}$, Faridah Zulkipli ${ }^{4}$, Siti Rozanae \\ Ismail $^{5}$, Normah Ahmad ${ }^{6}$ \\ ${ }^{1}$ Faculty of Computer and Mathematical Sciences, Universiti Teknologi MARA, Shah Alam, Malaysia, \\ sitikhatijahnor@tmsk.uitm.edu.my \\ ${ }^{2}$ AIM Solutions Sdn Bhd, Malaysia, amirhamzahjaafar@asgb.com.my \\ ${ }^{3}$ Faculty of Computer and Mathematical Sciences, Universiti Teknologi MARA, Tapah, Perak, \\ Malaysia, suray078@uitm.edu.my \\ ${ }^{4}$ Faculty of Computer and Mathematical Sciences, Universiti Teknologi MARA, Tapah, Perak, \\ Malaysia, faridah7368@uitm.edu.my \\ ${ }^{5}$ Faculty of Computer and Mathematical Sciences, Universiti Teknologi MARA, Tapah, Perak, \\ Malaysia, sitir919@uitm.edu.my \\ ${ }^{6}$ Faculty of Computer and Mathematical Sciences, Universiti Teknologi MARA, Tapah, Perak, \\ Malaysia,norma645@uitm.edu.my
}

\begin{abstract}
Students' performance in online learning has gained new interest due to the adaptation of Artificial Intelligence into the education sector. The Intelligent Tutoring System's evolution is still ongoing with continuous enhancement being embedded inside the system with various purposes related to learning measurement and performance evaluation. We have introduced a predictive function to determine the students' performance with respect to their peers. The enhancement will enable the system to predict the performance of the students based on the students' performance history and utilization of the intelligent system. Various data will be captured by the system to supply input to this predictive function. The new function considers time of independent study, confidence level during assessment, correctness of answers and average answering time for prediction. From the experiment and analysis conducted, we conclude that the new proposed predictive function is very accurate in predicting students' future performance.
\end{abstract}

Key words : Intelligent Tutoring System, Performance Evaluation, Predictive Function, Student Model

\section{INTRODUCTION}

The adaptation of Artificial Intelligence into the educational sector has made the teaching and learning process more effective. Intelligent Tutoring System (ITS) is a computer program that can be used in learning which uses some intelligence and has the ability to adapt to an individual learner. ITS is designed to imitate or simulate how human tutor acts and guide during teaching [1]. By including techniques from Artificial Intelligence (AI), ITS can be exactly like a good human tutor which is able to assist learners or students in attaining good understanding effectively during their learning.

ITS's main aim is to provide immediate and customized responses or instructions to learners; thus, it is just like a personalized tutor, which has a positive effect in stimulating students' learning interests [2]. In order to provide immediate feedback to learners, ITS must be able to interpret students' responses which are normally complex. ITS should be also able to estimate the degree of mastery of each student on the underlying knowledge of a particular subject. Through the mentioned capabilities, ITS's tutoring behaviour can be adjusted according to individual students.

Despite the many intelligent features introduced by researchers in ITS, some problems with the existing tutoring systems are mentioned in the literature which have attracted many researchers to keep on exploring and providing solutions on these issues. These problems include student performance measurements, prediction issues and problems of dealing with uncertainty in students' interactions. In the literature, researchers are actively improving the four main models in the ITS, which are the domain knowledge model, tutor model, student model and interface model [3]. Some of the works documented in the literature with regard to improving the ITS include [4][5][6][7]. There are some other recent works in enhancing the learning systems by employing intelligent components [8][9][10]. The ongoing works among research communities that are focusing on evaluating and predicting students' performance proved that the issues are of main concern in ensuring the ITS can work excellently. 
Motivated by the issues highlighted in the literature, this study is looking at enhancing the student model in ITS with the objective to propose a new method to measure and predict student performance and reduce the uncertainty in the students' interactions. For this purpose, new criteria and formulas are introduced to determine uncertainty and perform both performance measurement and prediction.

\section{METHOD}

The enhancement in the Student Model of ITS proposed in this study is to introduce a new method to measure the students' knowledge state and predict students' performance. Measuring students' knowledge state and predicting students' performance are both equally important in ITS to provide personalized assistance according to their knowledge state or mastery level on a certain knowledge domain and thus learning will be more effective. The following subsections will discuss these two proposed enhancements in detail.

\subsection{Measuring Students' Knowledge State}

A students' knowledge state is tested commonly by evaluating the students' performance in an exam. However, ITS opens an additional avenue to capture new data pertaining to students. Students'behaviour can be recorded and tracked using the ITS, how students behave, react and interact with the system provides additional information that can be utilized to provide new insights on the students' knowledge state. Utilizing the ITS we can monitor and record the followings: the students interaction time with the system or knowledge, the choices students make, the order of the students' action, the decisions, change of decisions and others [11].

We capture the elapsed time the students access the material in the system, through the interface and arrangement of the system we are able to know the amount of time a student spent on a particular material. We capture the time spent and the material knowledge area, this information provides insight on the following: we could derive the total time spent on a subject area, with the assumption the time spent will translate into knowledge in the subject.

Equation (1) below is proposed to calculate the Degree of Mastery of a student in a topic. A few important elements taken into the calculations are the confidence level (in answering questions), independent study time (recorded during learning using the system), correctness of answer and average time answering questions in a particular topic. More detailed explanations which expanded the function into sub functions can be found in [12].

$$
D M_{s t}=T I S_{s t} \times 0.2+C L D A_{s t} \times 0.1+C A_{s t} \times 0.5+A T A_{s t} \times 0.2
$$

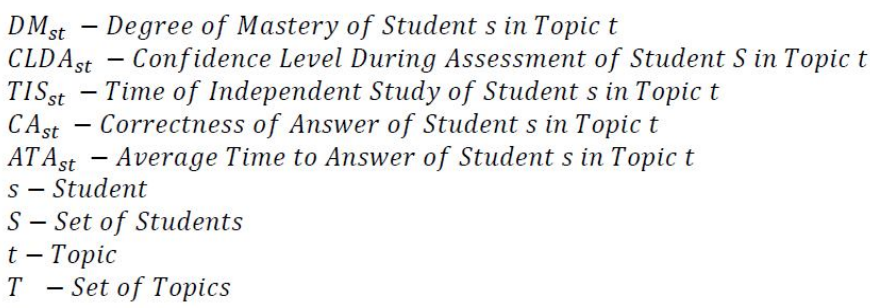

Each of the above element comprised in the function (from left to right) has a weightage of $20 \%, 10 \%, 50 \%$ and $20 \%$.

\subsection{Predicting Students' Performance}

By having the information on the knowledge state level of a student, together with the history of student's performance, prediction on the upcoming performance of the student can be made possible. Equation (2) is the prediction function proposed in our study.

$$
P E_{s e}=\sum_{a=1}^{|a|} \quad P Q\left(s, q_{a}\right), q_{a} \in E_{e}
$$

$$
\begin{gathered}
P Q\left(s, q_{a}\right) \\
=\left\{\begin{array}{c}
1, q_{a} \in E_{e}, a_{s q_{a}} \in A_{q_{a}}, v_{s q_{a}}=1, \\
0, q_{a} \in E_{e}, a_{s q_{a}} \in A_{q_{a^{\prime}}}, 0<v_{s q_{a}}<1, C D M>\left(v_{s q_{a}} \times 0.5+D M_{s t} \times 0.5\right) \\
1, q_{a} \in E_{e}, a_{s q_{a}} \in A_{q_{a}}, 0<v_{s q_{a}}<1, C D M \leq\left(v_{s q_{a}} \times 0.5+D M_{s t} \times 0.5\right) \\
0, q_{a} \in E_{e}, a_{s q_{a}} \notin A_{q_{a}}, C D M \geq\left(\operatorname{mean}\left(a_{s q}\right) \times 0.4+D M_{s t} \times 0.6\right) \\
1, q_{a} \in E_{e}, a_{s q_{a}} \notin A_{q_{a}}, C D M<\left(\operatorname{mean}\left(a_{s q}\right) \times 0.4+D M_{s t} \times 0.6\right)
\end{array}\right.
\end{gathered}
$$

CDM - Average Current Mastery Level of All students for All Related Topic

According to the above function, a student is predicted to answer correctly the next level assessment in a particular topic if the prediction value is more than $95 \%$ of the Degree of Mastery value. A detail explanation can be found in [12].

\section{EXPERIMENTS AND RESULTS}

In this section, we will explain the experiments carried out in this study. During the experiments, students were required to participate in an assessment after completing some independent study in the developed system. The system captured the necessary data to be pre-processed and supplied as inputs to the proposed functions employed in the system.

Figure 1 illustrates the screen shot of the ITS developed in this study during an assessment done by one of the students. This interface was captured a few seconds as soon as the assessment started; thus, it can be observed that all questions numbered 1 to 10 were not yet answered (indicated by the white buttons). 


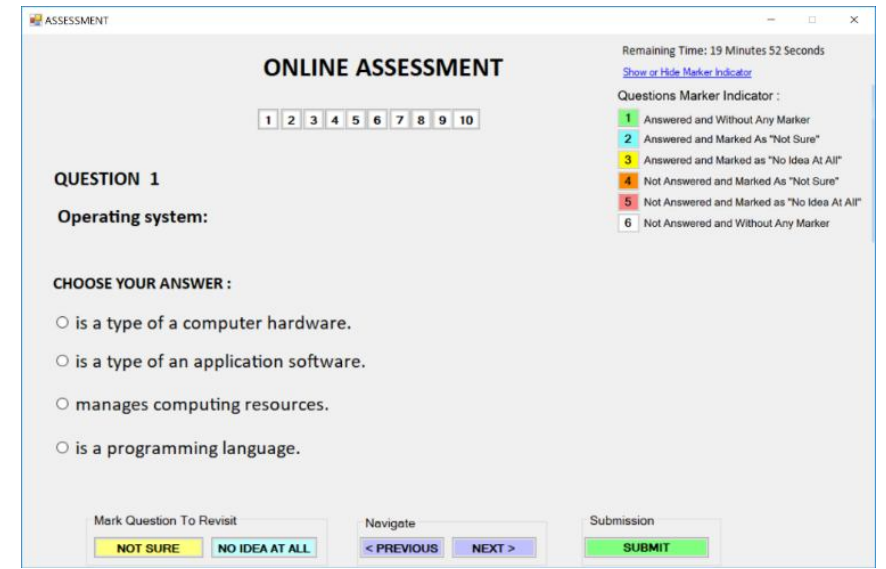

Figure 1: Screenshot of Interface at the Beginning of the Assessment

In the next figure (Figure 2), it can be seen the first button labelled with ' 1 ' which is referring to Question 1 is now in green color. This indicates that Question 1 has been answered and was not marked by the student. In terms of the level of confidence of students, this action is perceived in the student model as having a high confidence level towards the question. Even though this is captured by the system as having a high confidence in answering, it should be mentioned here clearly that this does not guarantee the student has answered the question correctly.

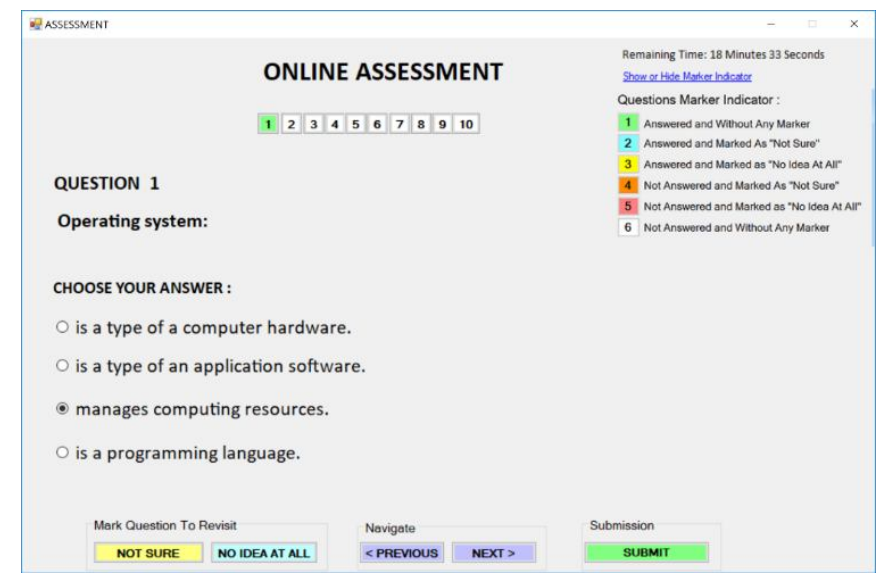

Figure 2: Screenshot of Interface After Student Answered Question 1

As the student progresses during the assessment, it can be seen in Figure 3 the student has not answered Question 2 and has marked it with "Not Sure". This is perceived by the system as the student having a low confidence level towards the question. (Note that the system only determines the correctness status of the answer after the student submitted the answers at the end of the assessment session).

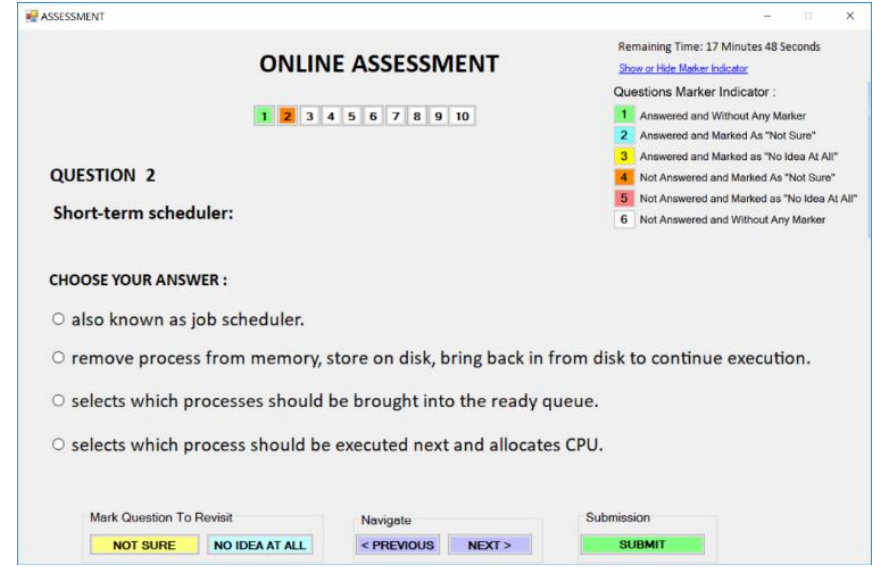

Figure 3: Screenshot of Interface After Student Visited Question 2

For explanation purposes, another screenshot is illustrated as in Figure 4, displaying the student is looking at Question 8. According to this diagram, the student has put markers on three questions indicating uncertainty in answering those questions.

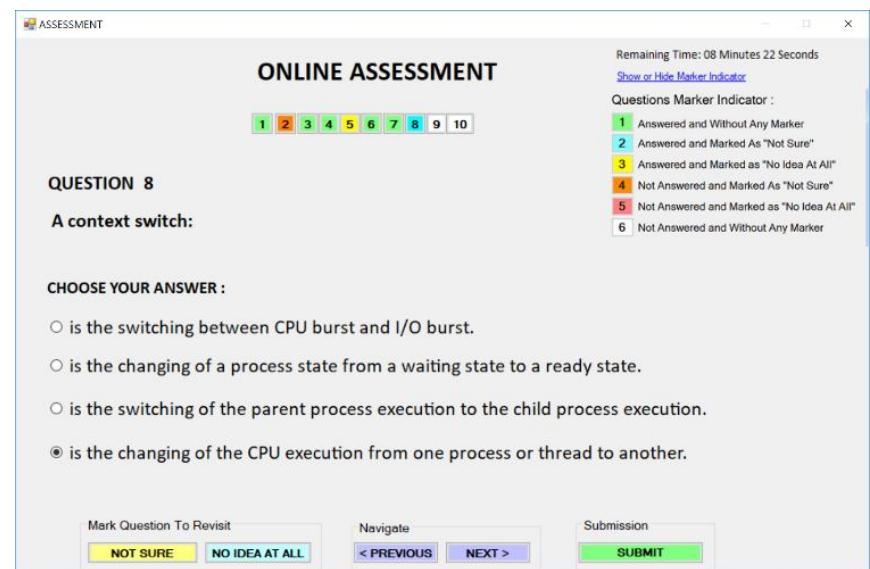

Figure 4: Screenshot of Interface After Student Answered Question 8

We have used a group of students in our experiment, in which they were asked to engage in learning, followed by an assessment using the developed ITS which employed the proposed functions in the Student Model. The main aim of this experiment is to evaluate their degree of mastery and predict their future performance on the same subject in the next assessment. Data required for both measurement and prediction processes were retrieved during and prior the assessment. For example, Table 1 illustrates the data captured for student S27 in terms of the markers selected on all questions (Question 1 until Question 10). 
Table 1. Data from Student's Assessment Used for Measuring Performance

\begin{tabular}{|c|c|c|c|c|c|c|c|c|}
\hline QNo & A & B & C & D & E & F & G & CL \\
\hline Q1 & 1 & 0 & 0 & 0 & 0 & 0 & 1 & 1.00 \\
\hline Q2 & 0 & 0 & 0 & 1 & 0 & 0 & 1 & 0.50 \\
\hline Q3 & 1 & 0 & 0 & 0 & 0 & 0 & 1 & 1.00 \\
\hline Q4 & 1 & 0 & 0 & 0 & 0 & 0 & 1 & 1.00 \\
\hline Q5 & 0 & 0 & 1 & 0 & 1 & 0 & 2 & 0.25 \\
\hline Q6 & 0 & 1 & 0 & 1 & 0 & 0 & 2 & 0.63 \\
\hline Q7 & 0 & 1 & 0 & 1 & 0 & 0 & 2 & 0.63 \\
\hline Q8 & 0 & 1 & 0 & 1 & 0 & 0 & 2 & 0.63 \\
\hline Q9 & 1 & 0 & 0 & 0 & 0 & 0 & 1 & 1.00 \\
\hline Q10 & 0 & 1 & 1 & 0 & 0 & 0 & 2 & 0.50 \\
\hline
\end{tabular}

(QNo: Question Number, A: Answered (No Marker), B: Answered (Not Sure), C: Answered (No Idea At All), D: Not Answered (Not Sure), E: Not Answered (No Idea At All), F: Not Answered (NO MARKER, G: Sum of Responses, CL: Confidence Level)

Based on the above table, it can be observed that for student S27, some of the questions were marked during the assessment. For example, Question 6 (Q6) was marked "Not Sure" and was not answered during the first visit to the question. Then it was answered later during the next visit to the question and the marker "Not Sure" was remain selected. (Observe column 'B' and 'D' are having value 1).

Each marker selection depending on the status of the question (either answered or vice versa), will have a penalty value as given in Table 2 below.

Table 2: Criteria and Penalty Used in the Proposed Approach

\begin{tabular}{|c|c|}
\hline Criteria & Penalty \\
\hline Answered and No Marker & 0 \\
\hline Answered and Marked "Not Sure" & 0.25 \\
\hline Answered and Marked "Not Idea At All" & 0.75 \\
\hline Not Answered and Marked "Not Sure" & 0.5 \\
\hline Not Answered and Marked "No Idea At All & 0.75 \\
\hline Not Answered and No Marker & 1 \\
\hline
\end{tabular}

Mainly for example purpose, below we present the calculation to determine the confidence level for student S27 on Question 8 according to the proposed mathematical function [11] [12].

1 - [ [ (Total answered $* 0)+($ Total answered and not sure * $0.25)+($ Total answered and not idea at all * 0.75) $+($ Total not answered and not sure $* 0.5)+($ Total not answered and no idea at all *0.75) + (Total not answered and no marker * 1$)]$ / sum of responses]

$$
\begin{aligned}
& =1-[[(0 * 0)+(1 * 0.25)+(0 * 0.75)+(1 * 0.5)+(0 * 0.75) \\
& +(0 * 1)] / 2] \\
& =1-[(0.25+0.5) / 2] \\
& =1-0.375 \\
& =0.63
\end{aligned}
$$

The average confidence level of all the questions can be simply calculated by summing up all the confidence level values for all questions and dividing it with the number of questions in the assessment (which is 10 questions).

Confidence level for Topic

$$
\begin{aligned}
& =(1+0.5+1+1+0.25+0.63+0.63+0.63+1+0.5) / 10 \\
& =0.71
\end{aligned}
$$

In the following, we will present the data obtained for student S27 in the experiment. Table 3 contains the data of the duration spent in answering questions during assessment. The duration for answering each question is recorded in second (s). For student S27, the average percentile of the duration taken by the student to answer all questions against all other students recorded was 42.11. This derived information will be used in the calculation to determine the level of mastery.

Table 3: Duration Taken by Student S27 During Assessment

\begin{tabular}{|c|c|}
\hline QNo & Recorded Time Taken To Answer \\
\hline Q1 & 100 \\
\hline Q2 & 44 \\
\hline Q3 & 25 \\
\hline Q4 & 19 \\
\hline Q5 & 181 \\
\hline Q6 & 84 \\
\hline Q7 & 90 \\
\hline Q8 & 97 \\
\hline Q9 & 45 \\
\hline Q10 & 150 \\
\hline
\end{tabular}

(QNo: Question Number, Q1: Question 1, Q2: Question 2, Q3: Question 3, Q4: Question 4, Q5: Question 5, Q6: Question 6, Q7: Question 7, Q8: Question 8, Q9: Question 9, Q10: Question 10)

Next, the derived data and values for measuring and predicting the performance for student S27 are presented in Table 4. These derived data are supplied as inputs to the predictive function. The output which is the prediction value obtained for this student is 9, and it is considered accurate as it only differs by 1 as compared to the real result obtained by the student in the real assessment.

Table 4: New Derived Value and Result for Performance Measurement \& Prediction for Student S27

\begin{tabular}{|c|c|}
\hline Derived Data (Pre-Processed Data) & Value \\
\hline Total Study Time & 32.00 \\
\hline Total Time / SLT & 0.84 \\
\hline Average Total Confidence Level & 0.71 \\
\hline Average Total Correctness of Answer & 0.80 \\
\hline Time Ranking(Average Percentile) & 0.42 \\
\hline Degree of Mastery & 72.39 \\
\hline Real Result Obtained (Actual Correct Answer) & 9 \\
\hline
\end{tabular}


At the end of the experiment (after students have completed the assessments) the students were ranked according to their degree of mastery obtained using the proposed formula. Table 5 tabulates the results obtained by the first 30 students sorted in a descending order according to the value of Degree of Mastery. The topmost rank is the student with the highest degree of mastery which means the student has the highest score (calculated using the proposed function), which indicates the student has the strongest underlying knowledge in the topic assessed.

Table 5: Measurements and Predictions Results

\begin{tabular}{|c|c|c|c|c|c|}
\hline No & SNo & $\begin{array}{c}\text { Degree } \\
\text { of } \\
\text { Mastery }\end{array}$ & $\begin{array}{c}\text { Predicted } \\
\text { Result }\end{array}$ & $\begin{array}{c}\text { Real } \\
\text { Result } \\
\text { Obtained } \\
\end{array}$ & $\begin{array}{c}\text { Prediction } \\
\text { Accuracy }(\%)\end{array}$ \\
\hline 1 & S16 & 86.82 & 9 & 10 & 90 \\
\hline 2 & S15 & 86.53 & 9 & 10 & 90 \\
\hline 3 & S11 & 85.32 & 9 & 10 & 90 \\
\hline 4 & S19 & 84.72 & 9 & 10 & 90 \\
\hline 5 & S7 & 84.23 & 9 & 10 & 90 \\
\hline 6 & S8 & 83.09 & 9 & 10 & 90 \\
\hline 7 & S6 & 82.58 & 9 & 10 & 90 \\
\hline 8 & S14 & 82.21 & 9 & 10 & 90 \\
\hline 9 & S30 & 81.8 & 9 & 9 & 100 \\
\hline 10 & S17 & 81.75 & 9 & 9 & 100 \\
\hline 11 & $\mathrm{~S} 2$ & 81.07 & 9 & 10 & 90 \\
\hline 12 & S20 & 80.96 & 9 & 9 & 100 \\
\hline 13 & S4 & 79.99 & 9 & 10 & 90 \\
\hline 14 & S33 & 79.07 & 9 & 9 & 100 \\
\hline 15 & S3 & 77.99 & 9 & 9 & 100 \\
\hline 16 & S9 & 77.04 & 9 & 8 & 90 \\
\hline 17 & S38 & 73.7 & 9 & 8 & 90 \\
\hline 18 & S27 & 72.39 & 9 & 8 & 90 \\
\hline 19 & S12 & 71.26 & 9 & 7 & 80 \\
\hline 20 & S18 & 66.11 & 8 & 6 & 80 \\
\hline 21 & S34 & 64.24 & 7 & 6 & 90 \\
\hline 22 & S13 & 62.84 & 6 & 5 & 90 \\
\hline 23 & S37 & 61.82 & 6 & 6 & 100 \\
\hline 24 & S1 & 60.84 & 5 & 5 & 100 \\
\hline 25 & S35 & 58.06 & 5 & 5 & 100 \\
\hline 26 & S29 & 55.48 & 3 & 4 & 90 \\
\hline 27 & S32 & 54.68 & 3 & 4 & 90 \\
\hline 28 & S5 & 54.12 & 3 & 4 & 90 \\
\hline 29 & S24 & 51.68 & 3 & 4 & 90 \\
\hline 30 & S23 & 50.97 & 3 & 3 & 100 \\
\hline
\end{tabular}

(SNo: Student Number)

It can be observed that the prediction on the students' performance is mostly differs only about $10 \%$ from the real result recorded. Difference in the prediction with the range +1 is considered very accurate (90\% accuracy). Therefore, since from the analysis made, only 2 students out of 30 students in total have an $80 \%$ accuracy, and the rest are $90 \%$ and above accurately predicted, so we can conclude that the method proposed in our study to measure and predict students' performance are very accurate and effective.

\section{CONCLUSION}

We have proposed a new method to measure students' knowledge state and predict student's performance. This is with the aim to improve the student model in ITS. We have developed an ITS which employed the newly proposed function. We then tested the new method by conducting an experiment on a group of students utilizing the ITS to learn and participate in assessments. From the experiments, it was observed that more than $90 \%$ of students in the dataset were predicted accurately in terms of their future performance. This basically proves that our proposed method for prediction is reliable and accurate, and it also indicates that the base function to measure the knowledge state of students is also equally reliable and accurate.

\section{ACKNOWLEDGEMENT}

The authors would like to take the opportunity to thank Universiti Teknologi MARA for the financial support to this project under ARAS Research Grant No. 600-RMI/DANA 5/3/ARAS (39/2015).

\section{REFERENCES}

1. Vanlehn. K. The behavior of tutoring systems, International journal of artificial intelligence in education, 16(3), 227-265, 2006.

2. Psotka. J, Massey. L. D, and Mutter. S. A. (Eds.). Intelligent tutoring systems: Lessons learned, Psychology Press, 1988.

3. Self.J.Theoretical foundations for intelligent tutoring systems, Journal of Artificial Intelligence in Education, 1(4), 3-14, 1990.

4. Greer. J andMark. M. Evaluation methods for intelligent tutoring systems revisited, International Journal of Artificial Intelligence in Education, 26(1), 387-392, 2016.

5. Lach. P. Intelligent tutoring systems measuring student's effort during assessment, In Canadian Conference on Artificial Intelligence (pp. 346-351). Springer, Berlin, Heidelberg, 2013.

6. Ramírez-Noriega. A, Juárez-Ramírez. R,and Martínez-Ramírez. Y. Evaluation module based on Bayesian networks to Intelligent Tutoring Systems, International Journal of Information Management, 37(1), 1488 1498, 2017.

7. Thai-Nghe. $\mathrm{N}$ and Schmidt-Thieme. L. Predicting Student Performance in an Intelligent Tutoring System, Doctoral dissertation, University of Hildesheim, 2012.

8. Vaganova. O. I, Smirnova. Z. V, Vezetiu. E. V, Kutepov. M. M, andChelnokova. E. A. Assessment tools in 
e-learning moodle, International Journal of Advanced Trends in Computer Science and Engineering, 9(3), 2488-2492, 2020.

9. Nwankwo. W, Umezuruike. C, and Njoku. C. C. Enhancing learning systems using interactive intelligent components, International Journal of Advanced Trends in Computer Science and Engineering, 9(3), 3390-3397, 2020

10. Singh. $\mathrm{R}$ and Pal. S. Machine learning algorithms and ensemble technique to improve prediction of students performance, International Journal of Advanced Trends in Computer Science and Engineering, 9(3), 3970-3976, 2020

11. Rahim. S.K.N.A, Jaafar. A.H, Masrom. S, Zulkipli. F, Ismail. S.R and Ahmad. N.Intelligent Tutoring System: New Criteria and Evaluation to Measure Students' Degree of Mastery,In Revision for International Journal Publication, 2020.

12. Rahim. S.K.N.A, Jaafar. A.H, Masrom. S, Zulkipli. F, Ismail. S.R and Ahmad. N.Enhancing the Measurement and Prediction Functions in Intelligent Tutoring Systems,Accepted for Publication in LNEE, Springer, 2020. 